\title{
Synchronous Videoconferencing in Distance Education for Pre-Licensure Nursing
}

\author{
John E. Scarbrough
}

Correspondence: John E. Scarbrough, School of Nursing, New Mexico State University, Las Cruces, NM, 88003, USA

\author{
Received: April 28, 2015 Accepted: May $122015 \quad$ Online Published: May 19, 2015 \\ doi:10.11114/jets.v3i4.797 URL: http://dx.doi.org/10.11114/jets.v3i4.797
}

\begin{abstract}
Current nursing education practices typically include methodologies for providing access to students located at a distance from the hosting institution. The majority of methodologies make use of asynchronous formatting in which communication occurs without the benefit of simultaneous, synchronous interaction. The increasing worldwide availability of high-speed internet access in combination with emerging technologies offer the opportunity to provide high-quality education to learners in remote and distant locations. The study examined student learner responses to two survey instruments upon the conclusion of a standard course in a pre-licensure baccalaureate nursing education program. Volunteer participants were solicited from an enrolled class of 21 students; 13 of the enrolled 21 students participated in the study. The selected instruments included the Distance Education Learning Satisfaction (DELES) and Social Presence Survey (SPS). The findings demonstrated equal or superior satisfaction and social presence scores on the selected instruments when contrasted with non-nursing coursework findings established in the literature using the same instruments. Significant generalizations from the pilot study are constrained due to the single-site, single-cohort design with small sample size, yet the findings support the belief that the synchronous methodologies afford a comparable, if not superior educational environment for distance learners. The findings further support the need for additional, expanded research to validate the initial findings and increase confidence in use of the new technologies.
\end{abstract}

Keywords: nursing, distance education, synchronous online videoconferencing

\section{Introduction}

In current discussions of distance education using online technology, there is lively debate concerning best practices seeking to motive, engage, and interact with students to maximize learning. When it comes to the topic of distance education, many nurse educators will readily agree that significant opportunity exists to develop and increase the availability of pre-licensure distance education for Registered Nurses using emerging synchronous electronic learning environments (Magnussen, 2006). Where this agreement ends, however, concerns the question of how best to deliver educational content to maximize student engagement, learning, and success in achieving educational outcomes. While some are convinced that nursing education as currently delivered via Learning Management Systems (LMS) infrastructure in an asynchronous manner may adequately meets the needs of students and faculty, others maintain that proper training and education for new nurses must always require in-person face to face interaction for didactic content. The debate concerning the delivery of education via electronic means encompasses not only nursing education, but higher education in general across multiple disciplines (Hill, 2012).

It should be stressed that, to date, there are no available methodologies completely able to substitute for hands-on training for psychomotor nursing skills or physical observation and interaction. Such components of nursing education still require the on-site physical presence of nurse educators, students, and patients in order to meet educational and experiential objectives. There is as yet no substitute for hands-on contact and interaction despite the very best of technological advances and electronic instrumentation.

New and emerging synchronous videoconferencing technologies, however, offer an exciting alternative for didactic course content through the ability to reach out to potential nurses and nursing students located at a distance from traditional educational institutions. The ability to connect synchronously and face to face in real-time with learners located both locally and/or at a distance offers excellent potential pathways for the achievement of the U.S. Institute of Medicine (IOM) goals to increase the numbers of Registered Nurses prepared by educational institutions (IOM, 2010). 
Clinical or hands-on education could be delivered remotely in small groups at distant sites, thus freeing students physically located at geographic distances remote from major centers of learning from requirements to relocate in order to gain a nursing education.

\subsection{Purpose}

The primary focus of the study was to investigate the ability of students to interact meaningfully in an educational setting using electronic synchronous technology (which affords face-to-face virtual interaction) without being physically present at a remote university location. The existing nursing shortage is exacerbated by limited student access to educational resources. For the vast majority of pre-licensure nursing students currently located in remote or distant regions in the United States, participation in a program of nursing education requires physical relocation to the area of the educational institution. The use of distance methodologies presents the opportunity to offer pre-licensure nursing education to the large numbers of qualified adult learners living in remote areas or at distances that would otherwise restrict their ability to obtain a nursing education. Such geographical challenges to education are not unique to nursing, and exist both within the United States as well as globally, where similar, largely rural areas with low population densities outside of major cities find themselves disadvantaged when it comes to access to education across multiple disciplines (Blake, 2000).

\subsection{Background}

A comprehensive review of existing literature found no evidence for the application of synchronous videoconferencing in use for nursing education. There has been significant exploration of ways to promote caring nursing behaviors in an online environment (Sitzman, 2010), as well as in-depth analysis of best practices for online nursing education (Plante \& Asselin, 2014). The prevalence of online education for nursing is highlighted by further research concerning exploration of additional communications tools available to online nursing education (Morely, 2014) as well as cheating in the online environment (Stonecypher \& Willson, 2014). Despite the abundance of research concerning online education in general and in nursing in particular, none of the available published data addressed the use of synchronous videoconferencing as a potential methodology.

Within traditional nursing educational arenas (requiring physical on-site presence), it is known that nursing students identify academic workload and related time management as significant stressors (Magnussen \& Amundson, 2003). Furthermore, it is known that undergraduate students frequently make use of virtual communication, social networking and media, smart phones, and computers as integral parts of their educational lives (Roblyer, McDaniel, Webb, Herman, \& Witty, 2010). Historical precedent involves the use of asynchronous methodologies for online distance instruction, taking advantage of written assignments, discussion groups, group projects, and online written quizzes. The increase in availability of high-speed internet connections and improvements in communications software have resulted in the development of opportunities to utilize synchronous learning via videoconferencing in to the electronic learning environment. Nursing education has made significant use of the asynchronous online educational environment with considerable success for post-graduate training. Findings by ElTahir (2010) strongly support the use of virtual tutoring in the provision of scaffolding strategies seeking to promote learner's awareness of thinking processes resulting in improved problem solving abilities for participants. A logical extension involves the extension of similar methodologies in to the primary didactic coursework for distance education.

\subsection{Instrumentation}

An early study was conducted to investigate the efficacy of online educational environments concerning student engagement and learning, and culminated in the development of the Distance Education Learning Survey (DELES) (Walker \& Fraser, 2005). The instrument seeks to quantify student perceptions of educational efficacy through the 6 identified domains of instructor support, interaction, relevance, authentic learning, active learning, and autonomy. Student responses to Likert-type scale items serve to assess student impressions of learning and satisfaction within distance education learning environments. The instrument has been validated as demonstrating construct validity through factor analysis, which found that the identified 6 domains effectively do represent measurement of the identified domains and no other. Reliability statistics for the instrument returned a Cronbach's alpha for internal consistency of 0.93 (Walker, 2003) across the 6 identified domains.

Subsequent use of the DELES has been demonstrated where 176 students who were enrolled in distance education and hybrid courses at a Spanish university were surveyed, and in which student participants responded anonymously to an electronic version of the instrument. The results demonstrated a Cronbach's alpha of 0.93 for reliability, and further established baseline data for the 6 identified domains of the DELES instrument (Ferrer-Cascales, Walker, Reig-Ferrera, Fernandez-Pascual, \& Albaladejo-Blazquez, 2011).

Similar conceptually-related research seeking to understand the potential implications of social presence in 
computer-based distance education and telecommunications has been undertaken (Gunwardena, 1995; Gunwardena \& Zittle, 1997; Richardson \& Swan, 2003). One study (Gunwardena \& Zittle, 1997) assessed the experiences of a total of 50 students from 5 different universities, all of whom participated in an inter-university virtual conference. One product of the identified study was the construction and development of an educational survey instrument, the Social Presence Survey (SPS), designed to assess students' perception of overall social presence (Gunwardena \& Zittle, 1997). Social presence is defined and interpreted as representing the degree to which a participant is experienced and perceived as "real" in mediated communication such as that experienced in online learning environments (Richardson \& Swan, 2003). The resulting Social Presence Survey (SPS) instrument demonstrated both construct validity and reliability where Cronbach's alpha $=0.88$ for the assessment of overall social presence (Richardson \& Swan, 2003).

Use of the two selected instruments (DELES and SPS) offer the opportunity to compare and contrast the experience of nursing students with those established by other students participating in distance learning but outside of the field of nursing. In keeping with the preceding data and identified need for improved distance education, the primary research question is identified as follows: "Is there a difference in student satisfaction and/or social presence in distance education online courses for distance learners participating in asynchronous learning environments when compared and contrasted with the addition of synchronous videoconferencing technology?"

\section{Methods}

Participation involved the anonymous completion of two satisfaction surveys distributed online to students participating in an online course delivered using synchronous videoconferencing technology for a regular university semester. Appropriate Institutional Review Board (IRB) approval from the sponsoring university was obtained prior to the commencement of any data collection. The selected survey instruments were distributed upon the conclusion of the university course term and after course scores had been reported, thus addressing any potential for perceived influence upon student participation and grade outcomes. The surveys utilized included the Distance Education Learning Environment Survey (DELES) (Walker \& Fraser, 2005) and the Social Presence Survey (SPS) (Richardson \& Swan, 2003). Permission to use both instruments was obtained through the corresponding authors prior to any data collection being undertaken in order to meet proprietary and copyright issues as well as to achieve IRB approval. Participants were requested to complete the selected feedback instruments in a single, voluntary online session, and no identifying information was collected at any point. The introduction to the surveys further stated that all items need not be completed for participation should a volunteer elect not to respond to a selected item or items. The total time estimated to complete both voluntary surveys was anticipated to have been 20 minutes. The resulting data obtained by the instruments were compiled and analyzed statistically using IBM SPSS Statistics $20^{\circledR}$ software (SPSS, 2011) to assess any differences in student satisfaction levels and social presence associated with the synchronous videoconferencing methodology when compared with findings from the literature and in the context of previous student coursework experiences which did not include the synchronous technology.

\section{Results}

A total of 13 students elected participate in the data collection phase, representing $61.9 \%$ of the total possible participants. Results of the DELES instrument found no statistically significant difference between the results by previous studies across 5 of the 7 domains measured (Ferrer-Cascales, Walker, Reig-Ferrera, Fernandez-Pascual, \& Albaladejo-Blazquez; 2011). Two of the domains did reveal a statistically significant difference between baseline measures and the synchronous videoconferencing group, where the synchronous teleconferencing group demonstrated significantly higher scores for Instructor Support $(\mathrm{p}=.015)$ and Interaction $(\mathrm{p}=.0016)$. The findings confirm that use of the synchronous videoconferencing methodology provide at least as good if not better satisfaction for student learners.

Similarly, results of the SPS survey identified no statistically significant difference between previous findings concerning the overall social presence experienced by students in asynchronous environments when contrasted with those of the synchronous videoconferencing context (Richardson \& Swan, 2003). The results of the study findings along with baseline data previously identified are presented in Table 1.

\section{Discussion}

Results of the survey demonstrated no statistically significant differences between asynchronous and synchronous distance methodologies across the broader spectra of satisfaction and social presence. It is interesting to note that a significant difference was detected in 2 of the 6 domains for the DELES (Instructor Support, and Interaction). Both perceived support from the instructor and interaction between students and instructor were 
Table 1. Study Results comparison

\begin{tabular}{|c|c|c|c|c|c|c|c|c|}
\hline \multicolumn{9}{|c|}{ Distance Education Learning Environment Survey (DELES) } \\
\hline & \multicolumn{3}{|c|}{ Subject Study Results } & \multicolumn{5}{|l|}{ Ferrer et al } \\
\hline Sample Size & $\mathrm{n}=13$ & & & $\mathrm{n}=92$ & & & & \\
\hline Domain & Mean & sd & $95 \% \mathrm{CI}$ & Mean & sd & $95 \% \mathrm{CI}$ & $\mathrm{t}$ & $\mathrm{p}$ \\
\hline Instructor Support & 4.79 & 0.54 & $4.31,5.26$ & 4.36 & 0.11 & $4.32,4.39$ & 2.86 & 0.015 \\
\hline Interaction & 3.29 & 0.96 & $2.44,4.13$ & 2.20 & 0.26 & $2.11,2.28$ & 4.07 & 0.0016 \\
\hline Relevance & 3.75 & 0.87 & $2.98,4.51$ & 3.97 & 0.14 & $3.92,4.01$ & -0.91 & 0.3824 \\
\hline Authentic Learning & 4.34 & 0.79 & $3.64,5.03$ & 4.12 & 0.15 & $4.07,4.16$ & 1.002 & 0.3388 \\
\hline Active Learning & 4.36 & 0.79 & $3.66,5.05$ & 4.20 & 0.17 & $4.14,4.25$ & 0.728 & 0.4834 \\
\hline Autonomy & 4.48 & 0.75 & $3.82,5.13$ & 4.28 & 0.11 & $4.24,4.31$ & 0.96 & 0.3574 \\
\hline Satisfaction & 3.18 & 1.17 & $2.15,4.20$ & 3.80 & 0.42 & $3.66,3.93$ & 1.893 & 0.0876 \\
\hline \multicolumn{9}{|c|}{ Social Presence Survey (SPS) } \\
\hline & Subject Study Results & & & Richards \& & wan & & & \\
\hline Sample Size & $\mathrm{n}=13$ & & & $\mathrm{n}=97$ & & & & \\
\hline Domain & Mean & sd & $95 \% \mathrm{CI}$ & Mean & sd & $95 \% \mathrm{CI}$ & $\mathrm{t}$ & $\mathrm{p}$ \\
\hline Overall Social Presence & 4.42 & 1.44 & $2.24-6.59$ & 4.39 & 1 & $2.40-6.37$ & 0.096 & 0.923 \\
\hline
\end{tabular}

Results of subject study when compared with baseline literature data for DELES and SPS found to yield more positive impressions from the learners in the synchronous environment when compared with baseline data from asynchronous environments. The results support the need for further investigation.

\subsection{Confounds}

Definitive conclusions from the study are necessarily reserved due to the small sample size and somewhat limited response rate. In addition, the data gathered referenced the experiences of a single group of students with a single instructor, within a single course, and within a single institution. Greater generalizability and confidence in results would have been possible had a larger number of students elected to participate in the study. A participation rate of $61.9 \%$ is encouraging, but in light of the small sample size of the larger cohort, definitive conclusions must be reserved.

One further constraint for future investigation of synchronous technology remains the issue of scalability. Increasing the size of the classes from a very manageable 21 students to cohort sizes ranging from 48 students to 130 students (which are not uncommon across major nursing education venues), presents scalability issues in which students could easily become 'lost' amongst the large number of classmates. Since these same issues of size present similar challenges in face-to-face classroom environments, the use of technology affords no relief from challenges associated with large class sizes. As an initial pilot study, it was deemed prudent to select a smaller class size for initial investigation prior to opening up the technology to larger classes of a more commonly-experienced size.

\subsection{Conclusions}

The findings were encouraging, but must be viewed with caution concerning generalization to a larger population from such a small, single-institution sample. Although the results of the study do support the belief that synchronous online learning environments making use of videoconferencing technology may offer the opportunity to improve student-faculty interaction and support, the need is clear for additional longitudinal studies across multiple courses and institutions in order to validate and confirm these tentative initial findings. The research presented herewith presents an initial foray in to what may prove to be a promising application of current technology to solve educational challenges for remote locations. In efforts to increase nursing education outreach for distance learners, the findings offer substantive support for continued pilot studies and investigation of technology in the preparation of future nurses.

\section{References}

Blake, N. (2000). Tutors and students without faces or places. Journal of Philosophy of Education Society of Great Britain, 34(1), 183-198. http://dx.doi.org/10.1111/1467-9752.00164

ElTahir, M. (2010). Virtual tutoring: An online environment for scaffolding students' metacognitive problem solving expertise. Journal of Turkish Science Education, 7(4), 3-12.

Ferrer-Cascales, R., Walker, S. L., Reig-Ferrera, A., Fernandez-Pascual, M. D., \& Albaladejo-Blazquez, N. (2011). Evaluation of hybrid and distance education learning environments in Spain. Australasian Journal of Educational Technology, 27(7), 1100-1110.

Gunwardena, C. N. (1995). Social presence theory and implications for interaction and collaborative learning in computer conferences. International Journal of Educational Telecommunications, 1(2/3), 147-166.

Gunwardena, C. N., \& Zittle, F. J. (1997). Social presence as a predictor of satisfaction within a computer-mediated conferencing environment. The American Journal of Distance Education, 11(3), 8-26. 
http://dx.doi.org/10.1080/08923649709526970

Hill, P. (2012). Online educational delivery models: A descriptive view. Educause Review, 84-97.

IBM SPSS Statistics Software. Available from http://www01.ibm.com/software/analytics/spss/

Institute of Medicine. (2010). The future of nursing: Leading change, advancing health. http://books.nap.edu/openbook.php?record_id=12956\&page=R1

Magnussen, L. (2006). Applying the principles of significant learning in the e-learning environment. Journal of Nursing Education, 47(2), 82-86. http://dx.doi.org/10.3928/01484834-20080201-03

Magnussen, L., \& Amundson, M. J. (2003). Undergraduate nursing student experience. Nursing and Health Sciences, 5, 261-267. http://dx.doi.org/10.1046/j.1442-2018.2003.00158.x

Plante, K., \& Asselin, M. E. (2014). Best practices for creating social presence and caring behaviors online. Nursing Education Perspectives, 35(4), 219-223. http://dx.doi.org/10.5480/13-1094.1

Richardson, J. C., \& Swan, K. (2003). Examining social presence in online courses in relation to students' perceived learning and satisfaction. Journal of Asynchronous Learning Networks, 7(1), 68-88.

Roblyer, M. D., McDaniel, M., Webb, M., Herman, J., \& Witty, J. V. (2010). Findings on Facebook in higher education: A comparison of college faculty and student uses and perceptions of social networking sites. Internet and Higher Education, 3, 134-140. http://dx.doi.org/10.1016/j.iheduc.2010.03.002

Sitzman, K. (2010). Student-preferred caring behaviors for online nursing education. Nursing Education Perspectives, 31(3), 171-178.

Stonecypher, K., \& Willson, P. (2014). Academic policies and practices to deter cheating in nursing education. Nursing Education Perspectives, 35(3), 167-179. http://dx.doi.org/10.5480/12-1028.1

Walker, S. L. (2003). Development and validation of an instrument for assessing distance education learning environments in higher education: The Distance Education Learning Environments Survey (DELES). Unpublished dissertation, Curtin University of Technology, Perth, Western Australia.

Walker, S. L., \& Fraser, B. J., (2005). Development and validation of an instrument for assessing distance education learning environments in higher education: The Distance Education Learning Environments Survey (DELES). Learning Environments Research, 8, 289-308. http://dx.doi.org/10.1007/s10984-005-1568-3

This work is licensed under a Creative Commons Attribution 3.0 License. 